\title{
Circuit
}

Musiques contemporaines

\section{Chronique des disques québécois}

Pauline Vaillancourt. La voix nue

\section{Jean-Jacques Nattiez}

Volume 3, numéro 1, 1992

Boulez au Canada : portrait d'impact

URI : https://id.erudit.org/iderudit/902044ar

DOI : https://doi.org/10.7202/902044ar

Aller au sommaire du numéro

Éditeur(s)

Les Presses de l'Université de Montréal

ISSN

1183-1693 (imprimé)

1488-9692 (numérique)

Découvrir la revue

Citer ce compte rendu

Nattiez, J.-J. (1992). Compte rendu de [Chronique des disques québécois :

Pauline Vaillancourt. La voix nue]. Circuit, 3(1), 107-108.

https://doi.org/10.7202/902044ar d'utilisation que vous pouvez consulter en ligne.

https://apropos.erudit.org/fr/usagers/politique-dutilisation/ 


\section{Pauline Vaillancourt : la voix nue Jean-Jacques Nattiez}

\section{Georges Aperghis : Récitations ; Giacinto Scelsi : Canti del Capricorno. Pauline Vaillancourt, soprano. Société nouvelle d'enregistrement (SNE- 571-CD).}

À coup sûr, ce disque est une gageure. Pauline Vaillancourt y déploie l'infinie diversité de sa voix pendant soixante-trois minutes en solo, sans que jamais l'attention de l'auditeur ou de l'auditrice se relâche un instant. La sélection habile des pièces ef l'ordre dans lequel elles sont présentées (dans le cas des Récitations, l'artiste a choisi le sien propre) y sont sans doute pour quelque chose. Nous sommes en présence, en tout cas, d'une réussite rare où la musicalité de l'écriture et de l'interprète est constamment au service d'un intérêt dramatique soutenu. Tous ceux qui ont eu la chance de voir Pauline Vaillancourt sur scène savent qu'elle est probablement l'une des *chantactrices * les plus douées de sa génération. L'une des grandes qualités de ce disque, c'est que, précisément, ceux ef celles qui ne pourront que l'entendre seront capables d'imaginer l'espace et la scène où évolue sa voix nue.

Les Récitations d'Aperghis sont fondées sur des syllabes souvent incompréhensibles ou sur des mots reliés par une syntaxe absurde, mais Pauline Vaillancourt déroule une parole qu' on ne comprend pas mais qui nous dit beaucoup. Qui parle? Grâce à la couleur propre aux différents registres, 
elle sait faire émerger plusieurs personnages d'une seule voix. Et d'un registre à un autre, d'une syllabe à une autre parfois, ce sont autant de profils psychologiques éclatés auxquels nous sommes confrontés: I'humour peut céder la place à l'obstination obsessive jusqu'à en devenir hypnotique, un filet de voix tranchant tire sa force de sa fragilité même, le ton de la confiance s'efface au profit de la dérision ou des inflexions aguichantes. L'intelligence - et le talent - de Pauline Vaillancourt, c'est, à tout moment, de parvenir à donner un sens à ce qui en semble privé.

Dans les Canti del Capricorno, le défi était d'une autre nature. Scelsi $s^{\prime}$ inspire des inflexions et du style de la lyrique japonaise, mais il attend aussi de son interprète qu'elle rende justice aux marges de la voix, comme Berio l'avait naguère demandé à Cathy Berberian. Avec un talent comparable, Pauline Vaillancourt sait donner une musicalité vraie à ce qui, autrement, pourrait aujourd'hui faire figure de maniérismes de l'écriture vocale contemporaine: percussions des consonnes, roulements des $r$, ouverture modulée des voyelles, tremblements des lèvres. L'artiste est tout particulièrement convaincante lorsque le chant oscille entre la complainte et le désespoir qui éclate en cris aigus, lorsqu'on ne sait plus si le compositeur veut régresser vers les premiers balbutiements de l'enfance ou nous prendre à témoin de la naissance d'un langage, ou quand, esquissant un chant populaire dont il ne resterait que des ruines, l'intensité quasi animale est poussée jusqu'au paroxysme.

Fautilil ajouter que ce disque, dont on souhaiterait qu'il devienne un classique du drame vocal contemporain, bénéficie d'une prise de son remarquable, où il y a juste ce qu'il faut de réverbération pour donner à la voix tout son relief et mettre en valeur le contraste des registres, la noblesse des graves et la finesse des élans aigus? 